\title{
Recursos midiáticos no Ensino de Ciências e Biologia
}

\author{
Media resources in Science and Biology Education
}

\author{
I. de Almeida ${ }^{1 *}$; L. J. Carvalho ${ }^{1}$; C. R. P. Guimarães ${ }^{2}$. \\ ${ }^{1}$ Programa de Pós-Graduação em Ensino de Ciências e Matemática, Universidade Federal de Sergipe, CEP 49100- \\ 000, São Cristóvão-Sergipe, Brasil \\ ${ }^{2}$ Departamento de Biologia/Núcleo de Ecossistemas Costeiros/ Programa de Pós-Graduação em Ensino de Ciências e \\ Matemática, Universidade Federal de Sergipe, CEP 49100-000, São Cristóvão-Sergipe, Brasil
}

ismael.almeida12@live.com

(Recebido em 22 de março de 2016; aceito em 22 de novembro de 2016)

\begin{abstract}
A mídia vem conquistando, cada vez mais, seu espaço na educação, sendo utilizada como suporte na aprendizagem, facilitando a vida dos estudantes e os atraindo para o processo educativo. Este trabalho visa destacar as contribuições que a tecnologia pode trazer para a escola e problematizar esses recursos, além de identificar o uso de recursos tecnológicos, pelos alunos, no Ensino de Ciências ou Biologia. Para tal, foi aplicado um questionário em uma turma do $2^{\circ}$ ano do Ensino Médio do Colégio Estadual Governador Valadares (Aracaju/SE), buscando respostas e opiniões relacionadas à utilização dos recursos midiáticos no universo escolar. Foi identificado que o recurso mais amplamente utilizado é o projetor multimídia. Com relação à utilização de recursos de mídia/informática nas aulas de Ciências e Biologia, 70\% dos discentes informaram que já tiveram aulas que faziam uso desses recursos. E todos afirmaram que a mesma é importante no processo de ensino e aprendizagem, reconhecendo-a como uma ferramenta na educação. Porém, ficou clara, também, a necessidade de promoção de uma alfabetização tecnológica para os professores que não detêm essas habilidades.
\end{abstract}

Palavras-chave: mídia; projetor multimídia; TICs.

The media is gaining more and more, its place in education, being used to support learning, facilitating the lives of students and attracting them to the educational process. This paper aims to highlight the contributions that technology can bring to the school and discuss these resources and identify the use of technological resources by students in Science or Biology Education. To this end, a questionnaire in a class of 2nd year of Eastern State Governador Valadares College Education (Aracaju / SE) was applied, seeking answers and opinions related to the use of media resources in the school universe. It was identified that the most widely used resource is the multimedia projector. Regarding the use of media resources / computer in class of science and biology, $70 \%$ of students reported that they have had classes that were using these resources. And all said that it is important in the process of teaching and learning, recognizing it as a tool in education. However, it became clear, also, the need to promote technological literacy for teachers who do not have these skills.

Keywords: media; multimedia projector; TICs.

\section{INTRODUÇÃO}

Mesmo com os grandes avanços científicos e com a introdução das Tecnologias da Informação e da Comunicação (TICs) no processo educacional, ainda é possível observar que o Ensino de Ciências e Biologia permanece, na maioria dos casos, restrito as aulas expositivas com mínima participação dos alunos nas aulas, o que leva a maioria deles a considerar que estas disciplinas estão entre as mais "complicadas e desinteressantes" do currículo escolar. Os conteúdos são memorizados por um curto período de tempo, apenas para a realização das avaliações, não ocorrendo de fato uma aprendizagem significativa e acarretando um ensino estático, desvinculado do cotidiano que dificulta o discente ser o sujeito de seu próprio aprendizado. Isso pode estar relacionado à sobrecarga de conteúdos, a pequena quantidade de tempo destinado a cada um deles, além da seleção descontextualizada desses conteúdos e a falta de valorização de conhecimentos prévios, poucas ou inexistentes aulas práticas e atividades lúdicas, entre outros fatores. 
O uso das tecnologias de informação e comunicação tornou-se uma necessidade no mundo em que vivemos. A sociedade atual não apresenta mais condições de conviver em harmonia sem as praticidades criadas pelas diferentes aplicabilidades dos meios de comunicação, que facilitam as relações sociais e possibilitam a proliferação do conhecimento.

Presente em todas as áreas, a mídia vem conquistando, cada vez mais, seu espaço na educação. Tecnologias quando introduzidas no ensino formal, a exemplo da internet, da televisão, vídeos, imagens, gráficos, jogos digitais, entre outras, com o objetivo de promover a educação e como suporte para a aprendizagem, facilita a vida dos estudantes e os atrai para o processo de aprendizagem.

A sociedade atual está se tornando cada vez mais midiatizada e, alguns professores estão incorporando meios tecnológicos em seus projetos políticos pedagógicos, como recursos para a produção das aulas. No entanto, outros ainda apresentam resistência para trabalhar com este tipo de recurso no ambiente escolar, por falta de conhecimentos suficientes na área. É possível alfabetizar tecnologicamente os docentes, por meio de formação continuada, para que estes, como profissionais, sejam competentes e responsáveis, no universo escolar, pela formação do alunado e a na tentativa de acompanhar os avanços da nova era tecnológica educacional.

Por meio desse trabalho foram investigadas as contribuições que a tecnologia pode trazer para o ambiente escolar, além de identificar o uso de recursos tecnológicos, pelos docentes, no Ensino de Ciências ou Biologia, buscando saber quais desses recursos midiáticos causam mais interesse e despertam maior curiosidade durante sua utilização nas aulas, sob o ponto de vista dos alunos.

\section{Recursos tecnológicos no ensino de Ciências e Biologia}

Os alunos apresentam dificuldades em aprender os conteúdos de Ciências e Biologia, pelo fato de que os assuntos são volumosos, complexos e dotados de termos complicados, além do fato de não existir conexão entre os assuntos abordados e o cotidiano do alunado, dificultando ainda $o$ processo de aprendizagem [1]. Ainda nessa perspectiva, outro problema relacionado a essas dificuldades é baseado no fato de que os conhecimentos que são repassados aos discentes, por meio do ensino tradicional, não partem de problemas que são recorrentes ao cotidiano desses indivíduos e, com isso, eles verão esses conteúdos como algo sem sentido, sem nenhum proveito em sua vida, utilizando apenas na escola [2].

Tavares [3] também discute que uma das principais dificuldades do método tradicional de ensino é o distanciamento entre o que está sendo estudado e o cotidiano vivenciado pelo discente, o que é um empecilho para uma aprendizagem significativa.

Ainda nessa mesma linha de raciocínio, Sobrinho [4] destaca que é imprescindível ter em mente a vontade de ensinar ou aprender Ciências e Biologia no processo de ensino, na qual a necessidade dessa aprendizagem deve ser vista pelo professor e, ao mesmo tempo, sentida pelo aluno como algo que seja útil em sua vida.

É necessário, portanto, que se procure uma maneira mais clara e compreensível de trabalhar os conteúdos referentes às Ciências Biológicas sem tornar os mesmos enfadonhos para o alunado, trabalhando em sala de aula com atividades diferenciadas e investigativas, fugindo assim do modelo de aula puramente expositiva e promovendo uma melhoria na aprendizagem ao tornar os assuntos mais atrativos e próximos da realidade dos alunos.

Uma das principais finalidades do sistema educacional é proporcionar aos futuros cidadãos capacidades de serem aprendizes mais flexíveis, eficazes e autônomos [5]. Partindo desta premissa e, na expectativa de reverter os problemas que afligem os modelos de educação nesse contexto, acredita-se que a inserção de novas práticas educativas, dentre as quais se destaca o uso de estratégias de ensino diversificadas, possam auxiliar na superação desses obstáculos que vem sendo enfrentados nessa área [6].

Para a transformação desse cenário, é necessário investimentos por parte do governo visando à formação continuada de professores, para que dessa maneira estes tenham acesso a uma nova forma de ver o "mundo da educação" e, assim, adquiram interesse em incrementar a sua prática pedagógica por meio da inserção de novas modalidades e/ou recursos didáticos, como saídas orientadas para museus e zoológicos, atividades práticas, modelos didáticos e jogos didáticos, 
além de vídeos e animações, como exemplo de recursos tecnológicos, objeto de estudo desse trabalho [7].

A definição de recursos e materiais didáticos são difusas e, muitas vezes, não há um consenso entre os educadores. A definição estabelecida por Cerqueira e Ferreira [8] talvez seja a mais condizente com os aspectos que estão sendo discutidos neste trabalho.

Recursos didáticos são todos os recursos físicos, utilizados com maior ou menor frequência em todas as disciplinas, áreas de estudo ou atividades, sejam quais forem as técnicas ou métodos empregados, visando auxiliar o educando a realizar sua aprendizagem mais eficientemente, constituindo-se num meio para facilitar, incentivar ou possibilitar o processo ensino-aprendizagem [8].

Já de acordo com Mercado [9], a expressão "novas tecnologias da informação" refere-se aos recursos tecnológicos que envolvem o uso de computadores e internet, que são o conjunto de processos e produtos derivados da informática, suportes de informação e canais de comunicação relacionados com o armazenamento, processamento e transmissão digitalizada de informações.

Os novos desafios exigem, na área educacional, a indicação de pistas e rumos capazes de preparar, em tempo cada vez mais curto, indivíduos de gerações e grupos diferentes para viverem em contextos sociais plurais e que requerem conhecimentos e domínios de habilidades permanentemente atualizados e continuamente articulados em termos de teoria e prática. Neste sentido, ganha força a defesa da tese da alfabetização científica e tecnológica [10].

$\mathrm{Na}$ tentativa de reverter este processo foram introduzidas as novas tecnologias de informação e comunicação, numa tentativa de dinamizar e facilitar a compreensão dos conteúdos ministrados.

É necessário superar o mito de que utilizar mídias na educação é uma tentativa de extinguir o professor no processo educativo. Com a utilização desses recursos, de modo crítico, podemos provocar os alunos a buscar entender a verdade sobre os "fatos" lançados na mídia, dominando assim a informação e a comunicação.

A instituição escolar deve alertar o jovem contra diversas formas de influência ou de manipulação midiática, tornando-o apto a uma atitude criativa em face das mídias, isto é, capaz de se apropriar de um máximo de informações originais a partir de uma visão pessoal de qualquer tipo de documento midiático.

A utilização das TICs, como ferramenta, traz muitas contribuições para a prática escolar, desde as séries iniciais até o ensino superior, apresentando múltiplas possibilidades de abordagem dos conteúdos.

Nessa perspectiva, Pimentel [11] sugere uma nova abordagem para os professores em sala de aula, frente às mídias:

Atrelada a esta concepção de mudança do paradigma está a compreensão de que o papel do profissional de educação na atualidade é o de estimular os alunos a aprenderem a buscar e selecionar as fontes de informações disponíveis para a construção do conhecimento, analisando-as e reelaborando-as [11].

Estamos vivendo a era tecnológica, na qual as crianças e os adolescentes estão fascinados pela tecnologia e é de grande importância refletir e questionar a conexão dessas novas mídias na escola na formação dos estudantes [12].

Moran [13] é determinante ao destacar que as novas tecnologias, que estão sendo inseridas no ambiente escolar de maneira gradativa, se constituem em pontes que abrem a sala de aula para o universo por se constituírem em novas formas de representação da realidade.

Com relação ao uso das tecnologias no ensino, Ruppenthal, Santos e Prati [12] destacam que:

A escola enquanto espaço social de aprendizagem entre pessoas deve se apropriar das tecnologias para tornar a aprendizagem prazerosa. Além do mais, elas permitem inúmeras formas de mostrar um conteúdo, privilegiando todos os sentidos, através da utilização de som, imagem, movimento. Dessa forma propiciam recursos para os mais variados estilos de aprendizagem.

Para Mota [14] a sociedade em que estamos inseridos está cada vez mais midiatizada, graças ao avanço das TICs, que possibilitam a integração entre indivíduos. Dentro desse contexto, o 
campo da aprendizagem social tem sido bastante favorecido com a utilização dos meios tecnológicos informacionais: os professores, ao incorporar em seus planejamentos didáticos os recursos tecnológicos, principalmente na produção das aulas, acabam viabilizando uma influência dos alunos com essa modernidade que vem sendo evidenciada na contemporaneidade [14].

Ainda de acordo com Mota [14], os educadores ao adotarem essas novas tecnologias de informação e comunicação, como suporte pedagógico, acabam provocando mais interesse dos alunos pelos conteúdos que são abordados em sala de aula e ainda possibilitam uma maior sintonia da educação com o contexto da modernidade.

No que se refere a grande disseminação das tecnologias entre os jovens e a relação conflituosa que pode ser estabelecida com o ambiente de ensino, Ruppenthal, Santos e Prati [12] defende que posicionamentos devem ser tomados pela escola diante dessa problemática:

Se no passado, a escola era o local para obter informações, hoje todos chegam à escola com informações diversas obtidas na TV, internet ou mesmo pelo rádio. Diante disso, percebe-se que a escola deve se preparar para trabalhar novas habilidades com os estudantes, a fim de que estes tenham uma visão crítica em relação a essas informações, bem como saber comparar, sintetizar essas informações ou então se posicionar com argumentos diante de questões polêmicas.

Pimentel [11] afirma que o uso das novas tecnologias ainda não se encontra incorporado nas escolas e nos diversos cursos na sua formação curricular. Destaca ainda que nem mesmo as antigas tecnologias ainda foram adequadamente incorporadas com convicção e apropriação de seu uso no planejamento dos professores e na sala de aula.

Para que as novas tecnologias sejam incorporadas no meio educacional com êxito, todos precisam de uma nova visão de mundo e de uma formação conectada com a sociedade tecnológica sustentável, pois também é inútil avançar, tecnologicamente, e termos num paralelo marginal uma grande parcela da sociedade excluída digitalmente e economicamente [11].

Mas a inclusão das TICs no processo educacional implica em outras questões que podem passar despercebidas. ARAÚJO [15], destaca isso:

O valor da tecnologia na educação é derivado inteiramente da sua aplicação. Saber direcionar o uso da Internet na sala de aula deve ser uma atividade de responsabilidade, pois exige que o professor preze, dentro da perspectiva progressista, a construção do conhecimento, de modo a contemplar o desenvolvimento de habilidades cognitivas que instigam o aluno a refletir e compreender, conforme acessam, armazenam, manipulam e analisam as informações que sondam na Internet.

O uso de mídias é parte integrante na vida contemporânea da maioria das pessoas que cada vez mais estão tornando-se adeptas destas tecnologias. No ensino, as mídias podem ser utilizadas como ferramenta didática, contribuindo para melhorar o processo de ensino e aprendizagem. A tecnologia não deve ser compreendida como substituta do quadro, livro didático e giz, mas como aliada da prática docente contribuindo significativamente para um aprendizado dinâmico e prazeroso.

\section{MATERIAL E MÉTODOS}

O presente trabalho foi desenvolvido no Colégio Estadual Governador Djenal Tavares Queiróz, localizado no município de Aracaju/SE, que oferece à população dessa região, todas as séries do Ensino Médio regular, com 458 alunos matriculados atualmente, tendo um IDEB de 1,6 (2013). Este índice é muito baixo, ficando abaixo do índice nacional, que corresponde a 3,7 (o Brasil não atingiu a meta para esse ano, que era de 3,9). Esse dado indica a necessidade de melhorias no processo de ensino e aprendizagem dessa unidade de ensino.

A pesquisa foi realizada com todos os alunos de uma turma do $2^{\circ}$ ano do Ensino Médio $(\mathrm{N}=20)$, do turno matutino, do referido colégio. 
Foi aplicado um questionário para avaliação da opinião dos alunos a respeito dos recursos midiáticos no processo de ensino e aprendizagem e os resultados foram transformados em percentuais de respostas.

Para discutir resultados alcançados nesse trabalho, foram utilizadas algumas respostas dos discentes, as quais foram representadas através de "E1...En", no qual "E" faz referência a "estudante" e a numeração que o acompanha, representa o aluno ao qual a resposta se refere.

É importante destacar que em algumas questões os motivos que justificaram as respostas dos discentes foram agrupados em várias categorias, de modo que, muitas vezes, o somatório das respostas ultrapassa o somatório dos respondentes.

\section{RESULTADOS E DISCUSSÃO}

Os alunos foram questionados a respeito de quais são os recursos que os professores das disciplinas de Ciências e Biologia fazem uso nas suas aulas. Os dados revelaram que o recurso didático mais utilizado pelos professores de Ciências e Biologia é o projetor multimídia (75\%), e logo em seguida vêm os jogos (30\%) e, por fim, com percentuais iguais (15\%), as aulas práticas e a utilização de vídeos.

Em conversa com o professor de Biologia da referida turma, o mesmo afirmou utilizar com maior frequência o projetor multimídia destacando a necessidade de abordar vários assuntos durante o ano letivo e acompanhar os diversos avanços científicos e metodológicos inserindo-os no cotidiano da sala de aula é uma tarefa complicada, com tão poucas horas semanais de aula e horários limitados de hora-atividade, o que acaba impedindo de produzir um material com antecedência de boa qualidade. Com isso, o projetor multimídia é uma alternativa viável para ele, já que está disponível no colégio e por meio da produção de aulas em power point, pode abordar o conteúdo de maneira dinâmica, mostrando imagens e esquemas que facilitam e aproximam os assuntos a realidade do aluno e não requer muito tempo para a produção.

A utilização de tecnologias multimídias na sala de aula vem ganhando cada vez maior destaque na educação e a utilização do recurso projetor multimídia em sala de aula já é amplamente disseminado nos espaços escolares, sendo o mais utilizado na sala de aula, logo após o giz, quadro e livro didático, que são tidos ainda como essenciais na promoção da educação.

As atividades escolares que utilizam recursos multimídia, na sua maioria, possuem grande apelo visual e acabam encantando professores e alunos através do layout, que apresenta cores vibrantes, som e movimento, deixando atraente o ambiente de aprendizagem.

Como essa tecnologia já é acessível na maioria das escolas é interessante a utilização desses recursos didáticos, com o intuito de obter um melhor rendimento no ensino e tornar a rotina escolar mais interessante.

É interessante destacar também o fato de que por meio da utilização desse recurso, todos os envolvidos no processo educativo são beneficiados; os professores, uma vez que as aulas ficam mais dinâmicas e o conteúdo com a exploração de imagens, fica mais fácil de ser explicado, e os estudantes, já que na maioria das vezes, o assunto passa a ser contextualizado com imagens regionais.

Para Faria [16], planejar uma aula com recursos tecnológicos, como todas as outras, exige preparo, dos materiais que serão utilizados, dos conhecimentos prévios dos alunos para manusear estes recursos, do domínio da tecnologia por parte do professor, além de seleção e adequação dos recursos à clientela e aos objetivos propostos pela disciplina.

Com relação à utilização de recursos de mídia/informática nas aulas de Ciências e Biologia, foi possível observar que $70 \%$ dos discentes já tiveram aulas que faziam uso desses recursos e, apenas uma pequena parcela (30\%), afirmou não ter aulas com esses recursos midiáticos.

Aliar os novos recursos tecnológicos que estão surgindo à atividade pedagógica pode significar dinamismo, criatividade e interação não só de conhecimentos teóricos, mas daqueles relacionados à vida dos estudantes. $\mathrm{O}$ uso pedagógico dessa rede poderá possibilitar aos professores e alunos uma nova forma de construção do processo de ensino e de aprendizagem [17].

Os alunos que responderam de forma positiva, à utilização de recursos midiáticos nas suas aulas, citaram como o mais utilizado o projetor multimídia (09 alunos), utilizado na apresentação 
de slides, seguido pela apresentação de vídeo (04 alunos). Apenas um aluno citou a utilização de computador ou notebook, provavelmente sendo utilizado para a realização de pesquisas em casa e não na própria escola. Os dados confirmam novamente a ampla utilização do projetor multimídia nas aulas de Ciências e Biologia.

Por este questionamento também foi possível identificar quais os conteúdos envolvidos por esses recursos. A zoologia apresentou o maior número de citações pelos discentes (6 citações), seguido pelos conteúdos que envolvem a botânica (4 citações). É importante destacar que houve um significativo número de discentes que apresentam respostas vagas (3 citações), como podemos ver em algumas citações: "Todos os assuntos" (E - 16); "A maioria das coisas" (E- 17); "Tudo" (E- 18). As respostas que apresentavam essas informações foram agrupadas na categoria "Maioria dos conteúdos". É possível destacar que a maior frequência de respostas encontradas nessa questão foi de ausência de respostas (11 citações). Isso pode indicar insatisfação, falta de vocabulário ou mesmo não lembram quais conteúdos estudados foram ministrados com a utilização de mídia.

Todos os alunos ao serem questionados sobre a importância da utilização da mídia no processo de ensino e aprendizagem das disciplinas de Ciências e Biologia responderam que ela é importante, reconhecendo-a como uma ferramenta na educação.

Nesse mesmo contexto, os discentes expuseram suas opiniões a respeito de como a mídia contribui no ensino. As respostas foram agrupadas em seis categorias (Fig. 01). Para a maioria dos alunos a utilização da mídia é importante por permitir uma melhor compreensão dos conteúdos. É possível perceber isso na citação de alguns discentes: "Porque ajuda na aprendizagem do assunto" (E-2), "Porque facilita a aprendizagem" (E-20).

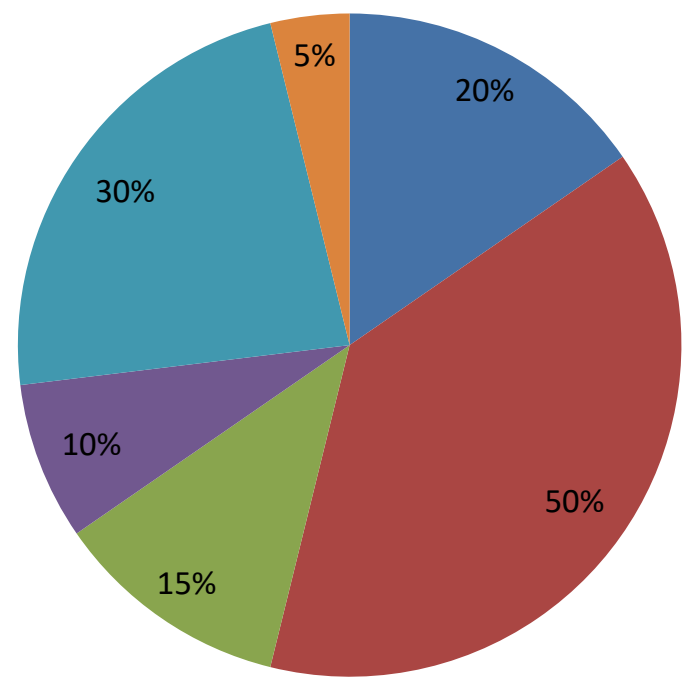

Facilita a explicação do
professor, expandido os
conteúdos
Melhor compreensão dos
conteúdos pelos alunos
Algo diferente do ensino
tradicional
Ajuda nas pesquisas escolares

- Motivação e torna a aula dinâmica

Figura 01: Justificativas para a importância da mídia no Ensino de Ciências e Biologia dada pelos discentes do Colégio Estadual Gov. Djenal Tavares de Queiróz. N=20.

Outros destacaram que a mídia é um elemento motivador na sala de aula, como citou o estudante E-17: "Se torna uma aula mais dinâmica". Logo em seguida, uma porcentagem menor dos alunos mencionou que por meio dos recursos midiáticos, a explicação do professor é facilitada e o mesmo pode expandir ainda mais os conteúdos, conforme foi observado nas seguintes respostas: "Porque com a utilização da mídia, o conteúdo pode ser expandido ainda mais, de acordo com o que o professor ministra" (E-5), "Facilita o trabalho do professor" (E-11). Outros acham a mídia importante, pois veem como algo diferente do ensino tradicional, que muitos docentes fazem utilização, como afirmou o estudante E-14: "Porque fica chato estudar somente com o ensino tradicional". E, por fim, uma pequena parcela dos estudantes destaca que a mídia é importante apenas para a realização de pesquisas escolares, como destacado na citação a 
seguir: "Com esses recursos fica mais fácil fazer pesquisas em vários sites, desenvolvendo ainda mais o que foi estudado" (E-6). Apenas 5\% não apresentaram justificativa para esse item.

As justificativas dadas pelos discentes, explicitam que a mídia, enquanto recurso didático na sala de aula, contribui na melhoria do aprendizado, além de motivar e facilitar o trabalho do professor.

Porém, é necessário ressaltar alguns problemas que podem ser desencadeados por meio da utilização da mídia online na escola, pois a mesma não está somente relacionada ao ensino, tem se percebido a grande inserção indireta das redes sociais nas escolas através dos celulares, que por vezes provoca conflitos entre professores e alunos. Isso se deve a crescente adesão do aluno às ferramentas digitais, disponíveis nos ambientes online.

Novais Souza e Sobral [18] abordam a utilização das redes sociais no processo de ensino e aprendizagem e, dizem que é possível promover a utilização desses dispositivos de forma cognitiva, mas para isso deve-se incentivar o estudo em grupos e a troca de conhecimentos, viabilizando a melhoria do rendimento escolar.

Por meio das redes sociais, é possível dar significado às experiências dos estudantes e serve também como espaço público de discussão sobre os mais variados temas, trabalhando assim as relações, os laços afetivos, a linguagem digital, além dos discentes se depararem com situações conflitantes sobre os mais variados assuntos, incluindo os conteúdos científicos.

As redes sociais cada vez mais vêm ganhando e atraindo seguidores de forma quase que descontrolada, sendo uma realidade nas escolas o uso das mídias em sala de aula , cabe então ao professor planejar atividades, com objetivos estabelecidos, utilizando como recurso as redes sociais.

Com relação ao IDEB desta escola, o mesmo continua baixo, mesmo com a utilização de recursos multimídia. Tal fato pode estar caracterizado pelo não uso frequente desses recursos, já que o colégio não apresenta suporte necessário para a implementação dessas atividades que envolvem tecnologias em sala de aula.

$\mathrm{Na}$ escola em que foi realizada a pesquisa, foi possível perceber alguns problemas: existe um laboratório de informática, com uma boa quantidade de computadores, no entanto, alguns destes estão em mau estado, evidenciando assim a falta de manutenção desses equipamentos, comprovando os argumentos citados anteriormente. Além disso, muitos discentes não utilizam os computadores de maneira correta, o que acaba danificando.

Os professores sentem-se na obrigação de utilizar aparatos tecnológicos, mas muitas vezes não tem formação, assistência técnica ou apoio dos funcionários da escola na organização dos tempos e espaços de utilização desses recursos. Isso nos remete ao analfabetismo tecnológico do professor e, isso é uma realidade encontrada nas mais diversas partes do território nacional. Mas, é possível alfabetizar os docentes através da formação continuada, para que estes apresentem domínio das linguagens utilizadas pelas tecnologias que estão à nossa volta e, em conjunto com o alunado, possam descobrir, compreender e interagir, contribuindo assim na modificação do mundo que nos cerca.

Quando não ocorre a apropriação desses recursos tecnológicos, com o aproveitamento de todas as potencialidades inseridas nesse recurso, acaba construindo a imagem de que esse ambiente escolar é desconectado do mundo ao seu redor.

É necessário destacar o fato de que nas aulas de Ciências e Biologia é de grande valia a utilização das aulas práticas, experimentos, investigações ou trabalhos de campo já que se tratam de estratégias eficientes na estimulação do interesse e da participação dos alunos em sala de aula, além de aproximar os conteúdos trabalhados em sala de aula com a realidade do aluno, na tentativa de conectar as experiências cotidianas com o pensamento reflexivo. Utilizando essas atividades e inserindo as TICs em sala de aula, o professor está levando aos educandos uma potencialização na articulação entre os conhecimentos, proporcionando assim um ensino de construção coletiva. 


\section{CONCLUSÃO}

Foi identificado que já há uma grande utilização de recursos tecnológicos, porém não de recursos online, pelos alunos e professores, no Ensino de Ciências e Biologia, principalmente o uso de projetor multimídia. A utilização das novas tecnologias de informação e comunicação, como ferramenta, traz uma grande contribuição para a prática escolar, nos variados níveis de ensino, como dinamizadora e facilitadora do processo de ensino.

Após a análise desse trabalho, algumas questões emergiram. Alguns professores não fazem utilização do laboratório de informática da referida escola. Seria escolha própria ou por não estarem aptos a desenvolver aulas utilizando esses recursos midiáticos?

\section{REFERÊNCIAS BIBLIOGRÁFICAS}

1. Fernandes HL. Um naturalista na sala de aula. Ciências \& Ensino. v. 5, p. 3-5. 1998.

2. Gomes FKS, Cavalli WL, BONIFÁCIO CF. Os problemas e as soluções no ensino de ciências e biologia. In: $1^{\circ}$ Simpósio Nacional de Educação: XX Semana da Pedagogia. Cascavel, 2008. http://www.unioeste.br/cursos/cascavel/pedagogia/eventos/2008/1/Artigo\%2055.pdf > Acesso em: 08 set. 2014.

3. Tavares PC. Utilização de jogo educativo como proposta para favorecer o ensino de ciências nas turmas do $8^{\circ}$ ano da Escola Municipal Maria Caproni de Oliveira, Município de Carvalhópolis MG. 2013.: <http://www.mch.ifsuldeminas.edu.br/ biblioteca/biblioteca_digital/Documentos/TCC-daBiologia2013/TCC-Priscila.pdf > Acesso em 08 set. 2014.

4. Sobrinho RS. A importância do ensino da biologia para o cotidiano. Fortaleza, 2009. Disponível em:< http://www.nead.fgf.edu.br/novo/material/monografias_biologia/RAIMUNDO_DE_SOUSA_SOBRIN HO.pdf $>$. Acesso em: 08 set. 2014.

5. Pozo JI. Aprendizagem de conteúdos e desenvolvimento de capacidades no ensino médio. In: Coll, César et.al. Psicologia da aprendizagem no Ensino Médio. Rio de Janeiro: Editora. 2003.

6. Pedroso CV. Jogos didáticos no ensino de Biologia: uma proposta metodológica baseada em módulo didático. In: Congresso Nacional de Educação - EDUCERE, 9., 2009, Curitiba. Anais. Curitiba: Graduação e Pós-Graduação em Educação da Pontifícia Universidade Católica do Paraná, 2009. P. 3182-3190.

7. Ribeiro AA. Experimentação no ensino de biologia: Revitalização de um laboratório didático em uma escola da rede pública do distrito federal. IV ENECiências, Brasil, mai. 2014. $<$ http://www.ivenecienciassubmissao.uff.br/index.php/ivenecienciassubmissao/eneciencias/paper/view/ 42>. Data de acesso: 17 mai. 2015.

8. Cerqueira JB, Ferreira EMB. Recursos Didáticos na Educação Especial. Instituto Benjamin Constante, Rio de Janeiro, 2007. < http://www.ibc.gov.br/?itemid=102 >. Acesso em: 10 set. 2014.

9. Mercado LPL. Formação continuada de professores e novas tecnologias. Maceió: EDUFAL, 1999.

10. Gouvea G, Leal MC. Uma visão comparada do ensino em ciência, tecnologia e sociedade na escola e em um museu de ciência. Ciênc. educ. (Bauru), Bauru, v. 7, n. 1, p. 67-84, 2001.

11. PIMENTEL, F. S. C. Interações no ambiente virtual de aprendizagem. In: II Seminário Web Currículo PUC-SP, 2010, São Paulo. Anais do II Seminário Web Currículo PUC-SP, 2010.

12. Ruppenthal R, Santos TL, Prati TV. A utilização de mídias e TICs nas aulas de Biologia: como explorálas. Cadernos de Aplicação, Porto Alegre, v. 24, n. 2, jul./dez. 2011

13. Moran JM. As mídias na educação. In: MORAN, J. M. "Desafios na Comunicação Pessoal”. $3^{a}$ ed. São Paulo: Paulinas, 2007, p. 162-166. Disponível em: <htpp://www.eca.usp.br/prof/moran/mídias_educ.htm> Acesso em: 10 set. 2014.

14. Mota DP. Mídia e educação: a Revista Nova Escola e sua contribuição para divulgação de ações educativas - análise de conteúdo da seção retrato. 2010. <http://www.artigonal.com/ensino-superiorartigos/midia-e-educacao-a-revista-nova-escola-e-sua-contribuicao-para-divulgacao-de-acoeseducativas-analise-de-conteudo-da-secao-retrato-3615846.html> Acesso em: 26 jul. 2014.

15. Araújo RS. Contribuições da Metodologia WebQuest no Processo de letramento dos alunos nas séries iniciais no Ensino Fundamental. In: MERCADO, Luís Paulo Leopoldo (org.). Vivências com Aprendizagem na Internet. Maceió: Edufal, 2005.

16. Faria, ET. O professor e as novas tecnologias. In: Ser Professor, ENRICONE, Délcia (Org.). 4.ed. Porto Alegre: EDIPUCRS, 2004.

17. Ramos OM.; Coppola NC. Uso do computador e da internet como ferramentas pedagógicas. 2009.

18. Novais Souza AA, Sobral MN. Redes sociais e ensino: possibilidades e desafios. Scientia Plena v.10, $\mathrm{n}$. 4, 2014. 